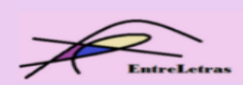

REVISTA ENTRELETRAS (ARAGUAÍNA), V. 12, N. 3, SET./DEZ. 2021 (ISSN 2179-3948 - ONLINE)

\title{
HISTÓRIA E LITERATURA EM DIÁLOGO: \\ VISÕES SOBRE O ROMANCEIRO DA INCONFIDÊNCIA MINEIRA (1953), DE CECÍLIA MEIRELES
}

\author{
HISTORY AND LITERAURE IN DIALOGUE: PERSPECTIVES OF “O \\ ROMANCEIRO DA INCONFIDÊNCIA” (1953), BY CECÍLIA MEIRELES
}

\author{
HISTORIA Y LITERATURA EN DIÁLOGO: \\ VISIONES SOBRE EL ROMANCEIRO DA INCONFIDÊNCIA MINEIRA (1953), DE \\ CECÍLIA MEIRELES
}

DOI 10.20873/uft2179-3948.2021v12n3p115-131

\author{
Celeste Maria Pacheco de Andrade ${ }^{1}$ \\ Cristian Javier Lopez ${ }^{2}$ \\ Weslei Roberto Candido ${ }^{3}$
}

\begin{abstract}
Resumo: Os diálogos entre o discurso da historiografia com a ficção possibilitam-nos um amplo espaço de reflexão sobre o poder das palavras e suas múltiplas interpretações. A confluência da História com a Literatura encontra nos gêneros híbridos um ponto de convergência importante para o estudo das ressignificações do passado, no intento do cultivo do pensamento decolonial. Neste artigo, apresenta-se uma breve reflexão sobre a relação desses dois ramos do saber, materializada em um poema histórico: o Romanceiro da inconfidência mineira (1953), de Cecília Meireles (1901-1964). São fundamentos da análise apresentada neste texto os pressupostos de Fleck (2017), Larios (1997), Burke (1993), Castro-Gómez e Grosfoguel (2007), entre outros.
\end{abstract}

Palavras-chave: História e Literatura; Literatura Comparada; Poema histórico; Literatura brasileira; Cecília Meireles.

Abstract: The dialogues between the historiographic and fictive discourse allow us a wide space of reflection about the power of the words and their multiple interpretations. The confluence of History and Literature finds an important convergence point in the hybrid genres for the study of remeanings of the past with the objective of cultivating decolonial thoughts. In

\footnotetext{
${ }^{1}$ Doutora em História: História Social pela Pontifícia Universidade Católica de São Paulo (PUC-SP). Professora Titular da Universidade do Estado da Bahia (UNEB). Integrante do grupo de pesquisa "Ressignificações do passado na América Latina: leitura, escrita e tradução de gêneros híbridos de história e ficção - vias para a descolonização". E-mail: candrade@uneb.br; ORCID: https://orcid.org/0000-0002-7308-8782.

2 Doutor em Estudos Literários pela Universidade de Vigo/Espanha em regime de cotutela com a Universidade Estadual do Oeste do Paraná/Brasil. Professor substituto de língua espanhola no Instituto Federal de Mato Grosso, campus Alta Floresta. Integrante do grupo de pesquisa "Ressignificações do passado na América Latina: leitura, escrita e tradução de gêneros híbridos de história e ficção - vias para a descolonização". E-mail: cristianjlopez2@gmail.com; ORCID: https://orcid.org/0000-0002-7391-8395.

${ }^{3}$ Doutor em Letras pela UNESP-Campus Assis. Professor Associado do Departamento de Teorias Linguísticas e Literárias da UEM - Universidade Estadual de Maringá. Pós-doutor pela Université Lumière Lyon 2 - France. Integrante do grupo de pesquisa "Ressignificações do passado na América Latina: leitura, escrita e tradução de gêneros híbridos de história e ficção - vias para a descolonização”. E-mail: wrcandido@uem.br; ORCID: https://orcid.org/0000-0002-8947-4266.
} 


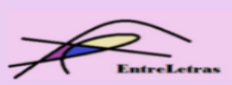

this article, we present a brief reflection of the relation between these two areas of knowledge materialized in the historical poem: "O Romanceiro da Inconfidência" (1953), by Cecília Meireles (1901-1964). The assumptions of Fleck (2017), Larios (1997), Burke (1993), CastroGómez and Grosfoguel (2007) are present in this analysis.

Keywords: History and Literature; Comparative Literature; Historical Poem; Brazilian Literature; Cecília Meireles.

Resumen: Los diálogos entre el discurso de la historiografía con la ficción nos posibilitan un amplio espacio de reflexión sobre el poder de las palabras y sus múltiples interpretaciones. La confluencia de la Historia con la Literatura encuentra en los géneros híbridos un punto de convergencia importante para el estudio de las resignificaciones del pasado en un intento de cultivar el pensamiento decolonial. En este artículo, se presenta una breve reflexión sobre la relación de esas dos ramas del saber, materializada en un poema histórico: o Romanceiro da inconfidência mineira (1953), de Cecília Meireles (1901-1964). Son fundamentos del análisis presentado en este texto los presupuestos de Fleck (2017), Larios (1997), Burke (1993), CastroGómez y Grosfoguel (2007), entre otros.

Palabras clave: Historia y Literatura; Literatura Comparada; Poema histórico; Literatura brasileña; Cecília Meireles.

\section{Introdução}

Os frutíferos diálogos entre as áreas da Literatura e da História, que na atualidade são uma profícua fonte de pesquisa dentro do âmbito da academia, contam com uma longa trajetória e passaram por um processo importante no que diz respeito à demarcação dos seus espaços de estudo e da sua atuação nas Humanidades. Até o século XIX “[...] a literatura e a história possuíam, em seus territórios até então comuns, uma função compartida: associar-se ao esforço humano da busca de orientação e compreensão do presente pelo revisionismo do passado, em busca de novas projeções para o futuro" (FLECK, 2017, p. 28). A partir do estabelecimento da divisão entre o discurso histórico e o discurso literário, foram produzidos numerosos estudos que buscaram delimitar as especificidades que tanto a História quanto a Literatura apresentam na atualidade. Entre essas especificidades podemos destacar aquelas que se referem ao corpus de seus estudos e à abordagem destes, assim como, também, às maneiras de registrar os fatos e o seu modo de transmiti-los às gerações. Nesse sentido, ambas as áreas do conhecimento, que apresentavam origens comuns e cujo material de trabalho era o mesmo - a linguagem/discurso - vêm suas delimitações definidas.

Desse modo, vemos que, mesmo resultantes de uma base comum - a manipulação da linguagem em um discurso articulado -, há diferenças entre os fundamentos de uma e outra áreas aqui relacionadas. A narrativa histórica e a literária são associadas, respectivamente, à construção discursiva da veracidade / "verdade", de um lado, e da verossimilhança, de outro. Isso estabelece entre elas também as devidas 


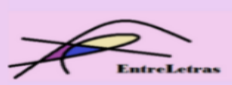

especificidades que as fazem ocupar espaços diferentes na estrutura organizacional do conhecimento: história é ciência e literatura é arte. (FLECK, 2017, p. 27).

Nesse sentido, História e Literatura são áreas cujas fronteiras têm alargado o leque de estudos, principalmente a partir do momento em que pesquisas históricas vêm ampliando temáticas e fontes. Por um lado, é uma expansão importante; por outro, tem trazido alguns questionamentos epistemológicos por parte de críticos literários e historiadores, desde que se considerem as respectivas formas de tratamento da narrativa. O historiador, usando do rigor da pesquisa, ao se apropriar de conceitos das ciências, busca as evidências que as fontes permitem e autorizam para reelaborar fatos e situações. Ele persegue coerência e plausibilidade para a sua análise. De acordo com White,

[...] o historiador deve 'interpretar' os seus dados, excluindo de seu relato certos fatos que sejam irrelevantes ao seu propósito narrativo... no empenho de reconstruir "o que aconteceu" num dado período da história, o historiador deve inevitavelmente incluir na sua narrativa um relato de algum acontecimento ou conjunto de acontecimentos que carecem dos fatos que poderiam permitir uma explicação plausível de sua ocorrência. E isto significa que o historiador precisa "interpretar" o seu material, preenchendo as lacunas das informações a partir de inferências ou de especulações. (WHITE, 1994, p. 65)

O ficcionista, livre desse rigor metodológico e do aparato técnico que faz parte do ofício do historiador, também produz crítica social e embora existam campos delimitados de atuação para cada um destes ramos do saber, ciência e arte, seus discursos convergem de maneira corriqueira em um tipo de produção profícua dentro do âmbito das letras: os gêneros híbridos de história e ficção.

A relação entre as duas áreas de conhecimento tem sido enfática em discussões na atualidade, quando se se debate os novos paradigmas da pesquisa histórica, fruto da superação da crise vivida pela própria história do conhecimento, na transição do século XIX para o XX. Apoiamo-nos na ideia de que, à medida que novas temáticas e novas abordagens passam a fazer parte da pesquisa histórica, ficamos diante de novos desafios, dentre eles, o que nos interessa no momento é, a relação e o diálogo entre História e Literatura.

Importante demarcar que esses dois territórios, a História e Literatura existem como fronteira, portanto, aponta para a convergência, ênfase deste projeto. A respeito da fronteira entre História e Literatura é pertinente a apreciação de Flávio Loureiro Chaves, que assim expressa:

O romance ofereceu à Literatura a dimensão de sua historicidade. Trata-se de momentos privilegiados em que a ficção assume a consciência política da sociedade. 


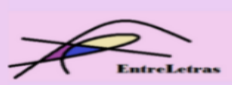

[...] instaurando a metáfora da tirania ou sugerindo a fronteira da liberdade, do Romantismo até aqui, História e Literatura reuniram-se no mesmo processo de sondagem e revelação da realidade brasileira. (CHAVES, 1999, p. 25)

A apreciação de Chaves (1999) leva-nos a refletir sobre as ligações entre esses dois campos do saber, atitude que não é recente, mas que não se esgotou, pois, muitas indagações permanecem a exemplo da busca da diferença, o caráter da especificidade de cada uma delas, as fronteiras, os limites entre a representação e a criação, o que sugere a possibilidade de confusão entre os dois discursos. A reflexão de Maria Teresa de Freitas é oportuna para a questão:

[...] as inúmeras catástrofes históricas da primeira metade do século XX foram suficientemente ricas em experiências humanas para fornecer vasta matéria à narração romanesca. [...] Por outro lado, a forma narrativa, que durante longo tempo caracterizara o discurso histórico - o que, aliás, provocou numerosos estudos sobre as semelhanças desse tipo de discurso com o da narrativa literária - desaparece pouco a pouco do domínio da História, e torna-se então a forma por excelência do discurso literário. (FREITAS, 1986, p. 13)

A relação entre as duas narrativas, a historiográfica e a literário-ficcional se apresenta a partir da narratividade e do seu conteúdo em termos de representação das realidades. Partindo das suas matrizes na história das mentalidades, a Nova História Cultural, baseia-se na nova configuração de objetos, campos de atuação e métodos diversos, enriquecendo o debate no que diz respeito aos conceitos, entre eles representações e imaginário. Sobre representação, Pesavento $(2005$, p. 42) afirma que "[...] o historiador da cultura visa, [...] a reconstruir com as fontes as representações da vida elaboradas pelos homens do passado". A historiadora acrescenta que, "a História Cultural se torna, assim, uma representação que resgata representações, que se incumbe de construir uma representação sobre o já representado [...]” (PESAVENTO, 2005, p. 43). Pesavento (2005, p. 43) entende que o imaginário, como conceito faz parte das mudanças epistemológicas da História Cultural e está intimamente associado com o estudo das representações, entendendo por imaginário "[...] um sistema de ideias e imagens de representação coletiva que os homens, em todas as épocas, construíram para si, dando sentido ao mundo.” (PESAVENTO, 2005, p. 43).

Nesse contexto, por exemplo, o gênero romance histórico é uma amostra concreta de como os discursos histórico e artístico continuam a ser, na atualidade, matéria prima para a criação literária em convergência com a História. Encontramos um número considerável de obras do gênero narrativo que, em suas diferentes modalidades, permitem a confluência dos discursos da História e da Literatura e terminam por ser produto muito difundido e comercializado, como é o caso do romance histórico. 


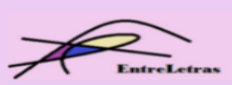

Outra questão que tem de se levar em conta é o fato de Literatura e História lidarem com a imaginação. De certo modo, ambas se voltam ao passado em busca de informações que sirvam de matéria à sua narração. A diferença está nos saberes que cada uma constrói: a história trabalha com o saber científico e a literatura com o saber narrativo. Assim, de acordo com Marco Aurelio Larios,

[...] no siempre ha sido claro el deslinde de la materia histórica en la literatura, ya sea por la interrogación sobre la exactitud y veracidad de los conocimientos, o por las inevitables modificaciones que la imaginación creadora suele permitirse en favor de la evocación histórica. Este conflicto nace de la hibridación entre los rasgos científicos de la historia y los rasgos estéticos del arte literario. En otras palabras, son dos saberes de discurso distinto: la historia se asocia con el saber científico y la novela con un saber narrativo. (LARIOS, 1997, p. 130).

Assim, a ficção latino-americana, principalmente, na necessidade de rever o seu passado colonial, hibridizou-se com o discurso histórico, borrando cada vez mais os limites entre História e ficção. Como foi comentado antes, a diferença fundamental entre essas duas áreas radica na maneira de lidar com o discurso e na construção de saberes. A Literatura tem a liberdade de rever personagens, recolocá-los no tempo/espaço da narrativa, tirando-os da obscuridade, fato que nem sempre o discurso histórico conseguiu realizar como deveria ser seu papel. Somente nos últimos anos é que a História tem se ocupado de revisitar o passado e rever algumas de suas posições. Assim, o discurso literário ocupa uma posição de vanguarda, uma vez que ousou ressignificar o passado, trazendo à tona personagens que são ambíguos, humanos, cheios de defeitos, que a história tradicional ocultou. Esse caráter vanguardista que pode ser encontrado na Literatura se deve a que

[...] a característica do poeta não é relatar o passado real, mas antes o passado possível, levando em conta as possibilidades dos acontecimentos segundo as verossimilhanças e a necessidade dos encadeamentos. $\mathrm{O}$ historiador e o poeta, com efeito, não diferem pelo fato de um narrar em verso e o outro em prosa - poder-se-ia ter transcrito em versos a obra de Heródoto e ela não seria menos história em verso do que em prosa. A verdadeira distinção é a seguinte: um narra o que aconteceu, o outro aquilo que poderia ter acontecido. (ARISTÓTELES In PINSKY, 1988, p. 144).

Com base nesse raciocínio de Aristóteles, podemos inferir que há, ao mesmo tempo semelhanças e diferenças entre a narrativa da Literatura e a narrativa da História e devemos demarcar essa diferença a partir das intenções da escrita, das estratégias escriturais disponíveis ao literato e ao historiador - demarcadas pelas áreas a que seus textos se filiam - e pela ideologia que perpassa cada uma dessas escritas (FLECK, 2017).

Nesse sentido, e ainda de acordo com Larios, 


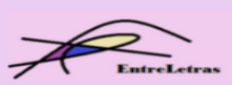

[...] tanto la construcción histórica como la literatura de estos hechos transitorios y concretos (datos históricos) se realiza mediante un doble procedimiento de interpolación. Allí donde el historiador interpola su narración histórica con datos que previamente ha seleccionado y criticado su veracidad, el narrador puede proceder con capricho o exceso narrativo. (LARIOS, 1997, p. 31)

Tanto a História quanto a Literatura manejam com a imaginação para representar o passado. Se ao narrador literário é permitido o excesso imaginativo para preencher as lacunas que não conhece, ao historiador cabe reconstruir o passado com a massa de informações que levantou em seu trajeto de pesquisa. Ambos os narradores têm como argamassa o passado, mas cada um assume uma postura diante do material ao qual tem acesso. Neste trabalho, os narradores literários levaram enormes vantagens em relação aos historiadores, pois, com o compromisso assumido com a imaginação, puderam rever personagens históricos e suas construções discursivas. Nessa perspectiva,

[...] há historiadores que se interessam em fazer leituras das obras literárias, mas frequentemente sem sucesso, pois as liam como se fossem um documento singular que ilustrava os resultados ou que corroborava o que as fontes e as técnicas clássicas da história tinham mostrado. Assim é uma leitura redutiva, puramente documental e que destrói o próprio interesse de se confrontar com a literatura. (CHARTIER, 2001, p. 91).

Nesse sentido, o campo da arte literária empreendeu um processo de descolonização intelectual na América Latina - uma tomada de consciência frente à 'colonialidade do poder' (CASTRO-GÓMEZ; GROSFOGUEL, 2007), em especial - muito antes do revisionismo histórico - empreendido pela nova história, em especial pela corrente da 'história vista de baixo' (SHARPE, 1992). Esse processo de enfrentamento, aberto e declarado, diante da versão oficializada do discurso hegemônico da história tradicional que consignou o passado das colônias latino-americanas, pela nova narrativa atingiu seu primeiro grande impulso no período do boom da Literatura latino-americana nas décadas de 19601 1970, perpetuando-se até nossos dias. Essas escritas híbridas romanescas têm sido via privilegiado dos povos latino-americanos cultivarem o pensamento decolonial.

De ahí que una implicación fundamental de la noción de 'colonialidad del poder' es que el mundo no ha sido completamente descolonizado. La primera descolonialización (iniciada en el siglo XIX por las colonias españolas y seguida en el XX por las colonias inglesas y francesas) fue incompleta, ya que se limitó a la independencia jurídico-política de las periferias. En cambio, la segunda descolonialización - a la cual nosotros aludimos con la categoría decolonialidad tendrá que dirigirse a la heterarquía de las múltiples relaciones raciales, étnicas, sexuales, epistémicas, económicas y de género que la primera descolonialización dejó intactas. Como resultado, el mundo de comienzos del siglo XXI necesita una decolonialidad que complemente la descolonización llevada a cabo en los siglos XIX 


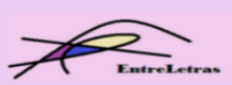

y XX. Al contrario de esa descolonialización, la decolonialidad es un proceso de resignificación a largo plazo, que no se puede reducir a un acontecimiento jurídicopolítico [...]. (CASTRO-GÓMEZ; GROSFOGUEL, 2007, p. 17).

O grande salto da Literatura foi assumir, muito antes dos historiadores, o discurso histórico como mais um discurso, portanto, passível de ser descontruído e, nesse trabalho, a imaginação pôde olhar o passado, desmistificando-o, pois

[...] as múltiplas significações do texto literário provocadas pelo ato de leitura dependem essencialmente do modo como o autor elabora as estruturas discursivas para que se alcance no texto a representação estética [...] para a elaboração do discurso ficcional é preciso que o autor tenha em mente a superação do abismo existente entre o conhecimento estético e o histórico. (OLIVEIRA, 2020, p. 254).

A liberdade no uso irrestrito de estratégias escriturais na composição do texto literário possibilitou à arte da palavra a produção de discursos ficcionais sobre o passado imbuídos tanto das premissas da descolonização - um processo de conscientização intelectual sobre o próprio sistema colonial, cujas reminiscências vigoram ainda em nossas sociedades - quanto os da decolonialidade - que projetam mudanças necessárias nas estruturas coloniais ainda resistentes para que as transformações rumo à democracia de fato se instaurem, mesmo a longo prazo. Para acelerar ainda mais esse processo de hibridação entre História e Literatura, um conjunto significativo de historiadores também mudou sua postura e deixou o discurso monológico em busca de outras vozes que pudessem compor o passado: "Nos hemos desplazado del ideal de la Voz de la Historia a la heteroglosia, definida como un conjunto de 'voces diversas y opuestas"” (BURKE, 1993, p. 18). Desde essa perspectiva, Peter Burke ainda ressalta que,

[...] en primer lugar, siguiendo el modelo de los novelistas que cuentan sus relatos desde varios puntos de vista habría la posibilidad de hacer más inteligibles las guerras civiles y otros conflictos. Es evidente que este recurso, tan eficaz en manos de Huxley) William Faulkner, en El ruido y la furia (1931), y Lawrence Durrell, en El cuarteto de Alejandría (1957-60) - por no mencionar las novelas epistolares del siglo XVIII -, no ha sido tomado con suficiente seriedad por los historiadores, a pesar de que podría ser útil modificarlo para tratar puntos de vista colectivos así como individuales. Un recuso así permitiría una interpretación del enfrentamiento a la manera de un conflicto entre interpretaciones. Para hacer que las 'voces diversas y opuestas' de los muertos se oigan de nuevo, el historiador necesita, como el novelista, practicar la heteroglosia. (BURKE, 1993, p. 295)

Como se nota, o historiador Peter Burke aponta para as vantagens da heteroglossia uma das estratégias escriturais privilegiadas nas escritas híbridas romanescas -, também para o discurso histórico. Para tanto, os historiadores deveriam se espelhar nos narradores literários, que foram os primeiros a conceberem a necessidade de compor suas narrativas com várias 


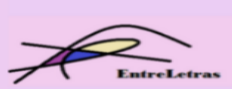

vozes, a fim de desfazer o discurso monológico do poder - que, entre outros meios, instaurou a 'colonialidade do poder'. Por meio da heteroglossia, os narradores literários puderam revisitar o passado e, muitas vezes, impugná-lo, ironizá-lo, desconstrui-lo em prol de uma leitura mais democrática, que incluísse as vozes de mulheres, negros, homossexuais - contingentes que sempre foram silenciados pela 'colonialidade do poder' - e que desconstruísse personagens históricos consagrados - estratégia do poder colonial para garantir modelos de homens às gerações colonizadas -, desvelando seus feitos e os analisando criticamente. No diálogo mais recente entre as duas áreas aqui aludidas, destacamos o fato de que,

[...] no campo da história, as relações dos discursos literários e históricos foram possibilitadas pela problematização epistemológica situada na diferença entre a 'passeidade' - o passado realmente acontecido - e a historiografia, ou 'a narrativa feita dele' pelo historiador, 'a sua recriação sob a forma de uma versão plausível'. Junto com isso, firmou-se uma 'convicção' de que os fatos passados não podem mais ser recuperados na sua concretude, sendo eles mesmos representações. (SOUZA, 2008, p. 46).

Portanto, é em busca de outras vozes que compõem o passado brasileiro, principalmente, o do período colonial, que o presente artigo pretende analisar fragmentos de uma obra híbrida de ficção e história que é o Romanceiro da Inconfidência, de autoria de Cecília Meireles (19011964), publicado em 1953. Deste modo, é importante ressaltar que não só os romances históricos - em suas diversas variantes - fizeram uso do discurso histórico, mas, também, outros gêneros, como o lírico e o dramático, voltaram-se sobre a narrativa histórica em busca de fontes para a sua inspiração. Assim, a arte da palavra apresenta dentro de seus grandes gêneros obras nas quais se estabelecem diálogos com a História, demonstrando a importância que tais discursos têm para o ser humano no seu ato de criação e transmissão do conhecimento.

\section{Romanceiro da inconfidência mineira: literatura e história em diálogo}

Para dar início à análise proposta, é pertinente comentar sobre alguns aspectos basilares para um melhor entendimento da obra artística. Dentre esses, destacam-se: a estrutura/forma utilizada pela poetisa para a elaboração da sua obra lírica, o contexto de produção do texto lírico e o sentido artístico do poema-objeto literário. Como primeiro ponto a ser destacado, precisase entender a forma lírica que Cecília Meireles utiliza na criação do seu objeto artístico. De acordo com o pesquisador português Carlos Ceia, o romanceiro é uma

[...] designação atribuída ao género literário de tradição oral constituído pelo conjunto de breves poemas tradicionais ou romances cuja origem remonta à Baixa Idade Média. Tal designação surge já em 1579 com a colecção de Lucas Rodrígues - Romancero Historiado -, sendo consolidada em 1600 com o Romancero General. Enquanto género, o romanceiro constitui o representante poético-narrativo da balada europeia 


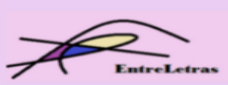

REVISTA ENTRELETRAS (ARAGUAÍNA), V. 12, N. 3, SET./DEZ. 2021 (ISSN 2179-3948 - ONLINE)

na Península Ibérica, apresentando, contudo, características próprias em relação às viser dinamarquesas, às bilinas russas ou às baladas escocesas e inglesas (CEIA, 2021, $\mathrm{s} / \mathrm{p})$

Importa, para o presente artigo, principalmente, a primeira parte da definição apresentada por Ceia (2021) sobre o romanceiro, que nos leva à sua tradição oral e ao conjunto de breves poemas que constituem o texto narrativo. Pode-se verificar, pelas origens desse gênero literário, que a heteroglossia é uma de suas características, pois, advém da oralidade e sua estrutura em conjuntos de pequenos poemas e temas é propício ao discurso de várias vozes. Nesse sentido, observa-se que a forma escolhida pela poetisa ganha importância pelo caráter popular da forma, para discutir sobre uma temática de relevância no âmbito que poderia ser importante ouvir outras vozes que na historiografia não estariam presentes. $O$ romance tradicional, expresso na forma poético-narrativa medieval de origem ibérica com forte base da tradição oral, evidencia o aspecto histórico-épico-lírico com traços da cultura popular. Essa combinação entre o narrativo do fato histórico e a reflexão lírica é o que se pode considerar de grande relevância já desde a escolha da forma.

A tradição oral, na trajetória humana como registro da memória, desde grupos que estavam à margem da escrita, como forma de recuperar recordações dos idosos e o registro de populações não letradas. Quando se trata da historiografia, a tradição oral passou a ser uma importante aliada a partir da Escola dos Annales e o desenvolvimento da História Social, que, aliada à memória passa a ter um lugar privilegiado no sentido de dar voz às chamadas "pessoas comuns". Essa perspectiva literária sobre o passado histórico integra a agenda das ações que buscam cultivar o pensamento decolonial nas antigas colônias Ibéricas na América. Nesse sentido, a partir das décadas de 1980 e 1990 essa tendência de História passou a ser grande aliada de pesquisadores das Ciências Humanas, entre elas a História, e de forma específica, para a História Cultural e a Nova História Cultural, resultando em importantes estudos e publicações.

Cecília Meireles, no ano de 1955, em Conferência proferida na Casa dos Contos em Ouro Preto (MG), afirma ver na cidade as reminiscências de uma Vila Rica por onde os inconfidentes passaram e sofreram com as perseguições. Cada parede, porta ou rua guarda em si o passado cruel a que foram submetidos os primeiros brasileiros a se levantarem contra a Coroa. A cidade respira a história e ao passado, que mesmo após duzentos anos continua a atormentar seus visitantes com os espíritos de Joaquim José da Silva Xavier, o Tiradentes, com a sombra de Joaquim Silvério, como se mesmo mudos, ainda pairassem com sua força sobre as paredes e seus habitantes. Assim podemos depreender do trecho que segue: 


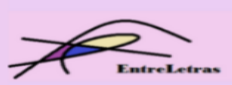

Então, na minha cidade, a visão de Ouro Preto e a lembrança de Vila Rica se sobrepunham ao cenário moderno e frívola da vida diária: a rua Gonçalves Dias apagava seus esplendores atuais: e apenas me obrigava a contemplar a provável porta do prateiro Domingos da Cruz, por onde desceu, preso - afinal! -, Joaquim José da Silva Xavier, o Tiradentes. E a rua da Assembleia gritava-me o caminho do mártir, até a forca. E a Igreja de Nossa Senhora da Mãe dos Homens contava-me a sua passagem por ali, em direção ao Paço, sob o olhar oculto do espião Joaquim Silvério (MEIRELES, 2008, p. 15).

Assim, o poema Romanceiro da Inconfidência (2008), composto por Cecília Meireles, é um misto de lirismo e história do Brasil. Se o poema é subjetivo pelo olhar poético que aborda o passado, não deixa de ser histórico, pois, a trama que dá corpo à narrativa, bem como os personagens constituem os fatos e o contexto de um período decisivo dos momentos préindependência.

O próprio título da obra remete a um evento da história brasileira, a Inconfidência Mineira, movimento de reação à política de exploração colonial por parte da metrópole portuguesa, principalmente a cobrança de impostos exorbitantes sobre metais preciosos explorados na Capitania das Minas Gerais. Era do conhecimento dos colonos o pagamento de impostos sobre a exploração dos metais preciosos, no entanto, um dos motivos que motivou a reação das Minas Gerais, em meados do século XVIII, foi a redução da extração dos minérios e, em contrapartida, não houve redução da arrecadação anual dos impostos, referente a cem arrobas de ouro.

Para melhor compreender essa relação de exploração é preciso trazer para esse contexto, a instituição da Derrama, por parte de Portugal. Esse instituto consistia na cobrança de impostos com base no número de habitantes e era aplicada através do confisco de bens e propriedades. Nesse particular, a Derrama afetava os mais ricos, parcela da população constituída por uma elite política e econômica, além de intelectuais, portanto, os mais interessados em reagir. Sobre esse caráter social, a exceção era o alferes Joaquim José da Silva Xavier, mais conhecido como Tiradentes.

O movimento dos inconfidentes retratava o descontentamento com a cobrança de impostos pela Coroa Portuguesa, exigindo dessa, a suspensão da cobrança. Mas, para além dessa pauta, estava o objetivo separatista, tanto do Brasil de Portugal quanto a criação de uma república correspondente à região das Minas Gerais. No entanto, pelo menos naquele momento, o movimento não veio a se concretizar e uma das causas foi o fato de ter sido delatado. Nesse contexto está a figura de Joaquim Silvério dos Reis, integrante do movimento. O processo no qual constava a confissão do delator teve como resultado a condenação de um dos líderes do movimento, Tiradentes, no ano de 1792. 


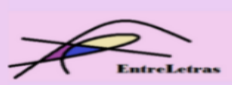

REVISTA ENTRELETRAS (ARAGUAÍNA), V. 12, N. 3, SET./DEZ. 2021 (ISSN 2179-3948 - ONLINE)

Através da lente da história estamos diante de fatos sobre um momento da história do Brasil colonial e que através da lente da ficção presente no Romanceiro da Inconfidência estão temas como a ação dos tropeiros, indivíduos que se destacaram no movimento na região da mineração, presentes de forma mais direta no romance número 30. Por isso, o poema de Cecília Meireles retrata os momentos decisivos da Inconfidência Mineira e o período de agitação política e pessoal de seus personagens. Amores, ódios, espionagens, pressões da Metrópole sobre os seus habitantes formam um conjunto de poemas líricos/históricos que narra a história do Brasil, filtrada pelo olhar poético que obriga o leitor a perscrutar as tensões íntimas que abalaram os envolvidos na trama pela libertação do Brasil. A "Fala inicial" do poema retrata bem o clima de tensão que cerca a cidade e seus habitantes: "Não posso mover meus passos/por esse atroz labirinto/de esquecimento e cegueira/em que amores e ódios vão:/— pois sinto bater os sinos,/percebo o roçar das rezas,/vejo o arrepio de morte,/a voz da condenação" (MEIRELES, 2008, p. 37).

Se há o clima de tensão entre as pessoas da cidade e que o poema tenta retratar na "Fala Inicial”, nela também há a data histórica e o peso de sua condenação: “Ó meio-dia confuso/ó vinte-e-um de abril sinistro,/que intrigas de ouro e de sonho/houve em tua formação?/ Quem ordena e quem pune?/ quem é culpado e inocente?" (MEIRELES, 2008, p. 38). Assim, a voz lírica denota as dúvidas que a distância temporal trouxe para quem se volta à data de vinte e um de abril. Quem são seus agentes, quem são os atores desta história? O eu-lírico se indaga, pois, é a história que vai contar ao longo dos oitenta e cinco romances mais uma "Fala aos Inconfidentes mortos"; é preciso, portanto, perscrutar o passado, revisitá-lo, lutar contra o esquecimento a que o tempo pode jogar seus personagens: "Na mesma cova do tempo/ cai o castigo e o perdão./Morre a tinta das sentenças/ e o sangue dos enforcados.../- liras, espadas e cruzes/ pura cinza agora são.” (MEIRELES, 2008, p. 38). Cabe ao poema resgatar seus atores, trazê-los de volta à memória da história pátria, dar humanidade aos seres de papel que os livros consagraram e, assim, cultivar o pensamento decolonial, cuja prática incita o leitor a revisitar as versões do passado e a se confrontar com elas, num intenso diálogo entre tempos e espaços.

É válido lembrar que o poema tem como figura central Joaquim José da Silva Xavier, o Tiradentes e que ele não é propriamente uma figura esquecida da história brasileira. Basta lembrar que vinte e um de abril, desde o ano de 1965 é feriado nacional, instituído pela Lei no 4.897, quando se comemora o dia do mártir da independência do Brasil. No entanto, a falta de um trabalho com a memória de Tiradentes banalizou o feriado no país. Falta ao personagem histórico sua carnadura, seu perfil e o questionamento dos motivos de sua morte. Deste modo, Romanceiro da Inconfidência, publicado originalmente em 1953, traz à tona uma leitura poética 


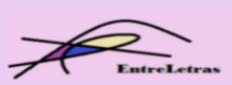

REVISTA ENTRELETRAS (ARAGUAÍNA), V. 12, N. 3, SET./DEZ. 2021 (ISSN 2179-3948 - ONLINE)

dos momentos decisivos da história do Brasil e com ela a humanização daquele que se tornou seu principal personagem.

De acordo com análise de José Murilo de Carvalho (1990), a figura de Tiradentes como parte da memória brasileira nasce em um contexto de pós-Proclamação da República (1989), regime que consolidava a separação, de fato, de Portugal. Esse contexto refere-se à busca pelos articuladores da república, de um herói para representar a nova forma de governo. No esforço em constituir essa figura, pois deveria possuir natureza estética e moral. Nesse caso, considerese o fato de que Tiradentes não era uma figura desconhecida por completo. Segundo historiador historiadores e literatos participaram do processo no sentido de justificar o nome de Tiradentes em relação do nome de D. Pedro I.

E quais os elementos que pesavam a favor do personagem Tiradentes para figurar como representação de imagem do Brasil, como herói? Considerando que a República buscava uma imagem que pudesse ser associada à nação brasileira, os elementos identificados foram: a) um dos resultados da Inconfidência Mineira foi a morte de Tiradentes por efeito de enforcamento; b) os acontecimentos relacionados com a Inconfidência Mineira e associados com a presença e ação de Tiradentes fazem parte de um espaço valorizado e significativo, do ponto de vista político e econômico, Minas Gerais; c) a tradição cristã da sociedade brasileira da época permitiu associar Tiradentes com a figura de Jesus Cristo, portanto, seria um Jesus Cristo Cívico; d) aliado a esse aspecto estava o fato de a morte de ambos personagens terem sido traídos, bem como a morte estar associada a calvário. Nesse caso, faltava, então, a semelhança física, o que não foi considerando a possibilidade do uso de recursos e apropriação pela arte para divulgar uma imagem, considerada naquele momento - 21 de abril de 1890 - como a ideal para a construção de um imaginário sobre a nação, e, em consequência a reprodução da imagem em quadros, monumentos e livros, entre outros suportes de exposição.

Nessa esteira de compreensão da relação entre Tiradentes e a representação da nacionalidade brasileira é oportuno uma avaliação de Wilson Martins: "É próprio dos mitos não coincidirem com a verdade, sendo-lhes igualmente peculiar tornarem-se talvez mais indispensáveis do que ela para a consciência coletiva. O que importa averiguar é como os mitos se constituem, que função mental exercem para consolidar o dogma da nacionalidade [...] e de que maneira acabam por tomar o lugar da verdade que a princípio pareciam idealizar." (MARTINS, 1980, s/p)

Ao que tudo indica, o poema tenta recuperar uma versão do passado que pode ter sido esquecida: "Na mesma cova, as palavras, o secreto pensamento,/as coroas e o machados/mentira e verdade estão." “Aqui, além, pelo mundo,/ossos, nomes, letras, 


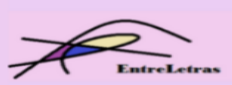

REVISTA ENTRELETRAS (ARAGUAÍNA), V. 12, N. 3, SET./DEZ. 2021 (ISSN 2179-3948 - ONLINE)

poeira..../Onde os rostos? Onde, as almas,?/Nem os herdeiros recordam/rastro nenhum pelo chão.” (MEIRELES, 2008, p. 38). Quando o poema foi escrito, no Brasil, a data de vinte de abril não era feriado, portanto, o esquecimento da figura de Tiradentes era maior ainda. E hoje, pode-se dizer que o feriado resolveu o problema do passado? Ou ao ler o Romanceiro da Inconfidência se tem a mesma impressão de 1953 de que se está em busca de respostas? O contexto do poema é tirar da "cova" do passado os fatos e tentar chegar a uma versão mais humana de quem foram seus personagens. É em busca desses personagens de extração histórica que os versos convidam o leitor a percorrer o poema.

\section{2 À sombra do Alferes}

O Romanceiro da Inconfidência está estruturado em uma "Fala Inicial", com versos em redondilha maior, nos quais o eu lírico apela ao passado, lutando contra o esquecimento da figura do Alferes. A voz lírica faz uma série de questionamentos sobre o tempo antigo e como ele fez com que muitos fatos se embaralhassem, precisando, por isso, serem remexidos para se chegar a uma possível verdade. Em seguida, o poema apresenta o "Cenário" das Minas Gerais, onde passaram os eventos da Inconfidência Mineira. Nessa parte do poema a versificação é clássica e os versos são decassílabos, talvez pela necessidade de se descrever a paisagem e as estrofes estão divididas em tercetos. Aqui o eu lírico assume a primeira pessoa, falando dos lugares por onde passou e que sentimentos suscitaram nele a paisagem mineira, como se o Alferes ao longe acenasse para ele, fato que brevemente voltaremos a comentar. Após apresentar o cenário, o romanceiro, enfim, começa com seus romances, que recebem um título, como por exemplo: "Romance I ou Da Revelação do Ouro”, Romance II ou Do Ouro Incansável etc. Nessas seções do poema, os versos voltam a ser redondilhas maiores, aproximando-se dos poemas antigos de tradição oral.

O cenário é uma parte lírica muito importante do poema, pois, é nele que se desenrolaram os acontecimentos da Inconfidência Mineira. Descrita de forma poética, a voz lírica passeia pelos belos campos mineiros, onde começa a ouvir a voz do passado. "Que vento, que cavalo, que bravia/ saudade me arrastava a esse deserto/me obrigava a adorar o que sofria?" (MEIRELES, 2008, p. 40).

E, assim, passeando pelos campos o eu lírico conversa com a natureza, ouve o passado, "Vencendo o tempo, fértil em mudanças, / conversei com doçura as mesmas fontes, e vi serem comuns nossas lembranças" (MEIRELES, 2008, p. 40). A voz lírica se irmana à natureza e descobre nela fontes comuns de memória, o que permitirá ouvir as vozes do passado, que essa terra esconde. 


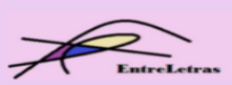

REVISTA ENTRELETRAS (ARAGUAÍNA), V. 12, N. 3, SET./DEZ. 2021 (ISSN 2179-3948 - ONLINE)

Ao se misturar à natureza, o eu lírico passa a entender sua voz e o que ela encobre passa a descoberto aos seus olhos. O passado se descortina por meio da natureza, revelando o que ocorreu nessas belas terras: "Tudo me fala e entendo: escuto as rosas/e os girassóis destes jardins, que um dia/ foram terras e areias dolorosas/por onde o passo da ambição rugia;/por onde se arrastava, esquartejado, /o mártir sem direito de agonia" (MEIRELES, 2008, p. 41). Aqui, pela primeira vez, no cenário, aparece a sombra do Alferes. Estas belas terras, onde a natureza convida à contemplação foi o caminho da morte de Tiradentes, que passa esquartejado sem direito nem sequer à agonia. A bela natureza mineira esconde um passado de violência, que vai sendo revelado ao eu lírico.

Uma vez despertada a voz lírica ao passado que a natureza oculta: "Tudo me chama: a porta, a escada, os muros, / as lajes sobre os mortos ainda vivos, / dos seus próprios assuntos inseguros." (MEIRELES, 2008, p. 41). O passado convoca o observador a encontrar respostas, até os mortos, metaforicamente, ainda estão vivos e têm assuntos pendentes. Cabe ao eu lírico revelar o passado aos olhos do presente, é uma incumbência como se pode ver nos versos seguintes: "E assim me acenam por todos os lados. /Porque a voz que tiveram ficou presa/na sentença dos homens e dos fados" (MEIRELES, 2008, p. 42). Em outras palavras, o passado não está resolvido e cabem novas interpretações. É nesse sentido, que este poema é um texto híbrido de história e ficção, no qual discurso histórico e narrativo se imbricam em busca de uma interpretação ideal do passado: "por asas de memória e de saudade, / com o pó do chão meu sonho confundia" (MEIRELES, 2008, p. 42). Essa intencionalidade da escrita poética condiz com as premissas da escrita híbrida de história e ficção latino-americana na qual se revelam as ainda necessárias reflexões e ações decoloniais frente à memória coletiva fraturada que um estado colonial impôs sobre o modo de ser, de pensar e de agir dos sujeitos colonizados.

Nessa confluência entre História e ficção também há espaço para o amor, e antes que o Alferes surja efetivamente no cenário, como o inevitável personagem a ser compreendido, o eu lírico lança o olhar aos amores que este episódio violento da Inconfidência Mineira gravou nas páginas da história do Brasil. São convocadas à cena as Isabéis, Dorotéias e Eliodoras que foram separadas de seus amores pela morte ou pelo degredo: "Isabéis, Doretéias, Eliodoras/ao longo desses vales, desses rios,/viram as suas mais douradas horas/em vasto furacão de desvarios/vacilar como em caules de altas velas/cálida luz de trêmulos pavios" (MEIRELES, 2008, p. 43). Como é possível observar, aqui o carácter subjetivo expressivo do gênero lírico convida aos leitores a uma aproximação com as personagens desde uma visão mais íntima. Nesse sentido, vê-se que o poema histórico conjuga as personagens de extração histórica e os 


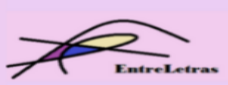

REVISTA ENTRELETRAS (ARAGUAÍNA), V. 12, N. 3, SET./DEZ. 2021 (ISSN 2179-3948 - ONLINE)

fatos com a subjetividade do eu lírico, permitindo uma identificação de quem lê com sentimentos possíveis que poderiam ter acontecido no âmbito do passado.

E, assim, ao final do "Cenário", o passado ainda perturba o eu lírico que busca respostas. O passado parece hermético, mas a sombra do Alferes convoca a voz lírica a se lançar na aventura de contar a sua versão da Inconfidência Mineira: "O passado não abre sua porta/e não pode entender a nossa pena/Mas, nos campos sem fim que o sonho corta/ vejo a forma no ar subir serena:/ vaga forma, do tempo desprendida. /É a mão do Alferes, que de longe acena." (MEIRELES, 2008, p. 44).

A despedida do Alferes da voz lírica é um aceno do passado que a provoca a percorrer o caminho de Tiradentes. Esse adeus que fez estremecer o observador atento da natureza de Minas Gerais, gerará mais de oitenta romances, nos quais se refaz os momentos decisivos da Inconfidência. Ao mesmo tempo que a mão acena em despedida, ela é um convite para mergulhar no passado em busca de respostas. O Romanceiro da Inconfidência, assim, torna-se via para o cultivo do pensamento decolonial, de questionamentos e de suposições, de versões outras sobre o passado colonial do Brasil.

\section{Considerações finais}

As perspectivas que a arte da palavra oferece sobre o passado, graças a seu carácter polissêmico, possibilitam que dentro do âmbito literário se possam ressignificar acontecimentos que o discurso histórico tem consagrado ao longo do tempo. Nesse sentido, o poema histórico permite, com sua particular subjetividade, criar um olhar diferenciado sobre os fatos históricos desde o lugar de um eu lírico que leva aos leitores a questionamentos pessoais sobre "aquilo que aconteceu" contra "aquilo que poderia ter acontecido".

No Romanceiro da inconfidência, Cecilia Meireles explora um fato relevante para a história do Brasil, na voz singular e subjetiva do poema, e desenvolve uma série de imagens que recriam o cenário histórico, as personagens históricas e as ações que tiveram lugar em 1789. A forma utilizada para a elaboração do poema caracteriza-se como uma construção lírica em relação com a tradição oral, detalhe altamente relevante para a criação de um discurso sobre um fato histórico. Em outras palavras, apresenta-se uma parte da história do Brasil na voz popular que a forma do romanceiro contém, trazendo a ideia de que o acontecimento tem relação com o sentir e dizer do povo. A forma utilizada explora o caráter de tradição oral que passa de geração a geração um fato histórico de relevância.

O tratamento que, no caso analisado, a literatura realiza sobre o fato histórico passa a ser importante ao se pensar em que o romanceiro foi publicado ainda em uma data anterior à 


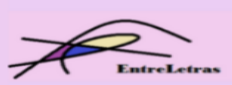

REVISTA ENTRELETRAS (ARAGUAÍNA), V. 12, N. 3, SET./DEZ. 2021 (ISSN 2179-3948 - ONLINE)

incorporação do fato histórico ao calendário do país como uma data comemorativa. A poeta estabelece, no âmbito da criação literária, um romanceiro, aquilo que popular e historicamente era de importância antes de ser considerado pelo estrato social, legal e político como seria o reconhecimento do dia vinte e um de abril para a história brasileira.

Desse modo, os diálogos entre as duas áreas permitem, de forma concreta, a construção de um caminho necessário à formação da sociedade brasileira. A discussão sobre o discurso histórico e a sua veracidade desde a perspectiva literária e sua proposta desde a verossimilhança, é uma ação pertinente na atualidade para uma educação da criticidade no cidadão latinoamericano.

Espera-se que as breves reflexões expostas neste texto possam contribuir com os estudos que visam a uma, ainda necessárias, descolonização do pensamento e revisão do passado histórico do Brasil pelo cultivo do pensamento decolonial.

\section{Referências}

ARISTÓTELES. Poética. In PINSKY, Jaime. 100 textos de História Antiga. 4 ed. São Paulo: Contexto, 1988.

BURKE, Peter. Formas de hacer la historia. Tradução de José Luis Gil Aristu. Madrid: Alianza Editorial, 1993.

CEIA, Carlos. Romanceiro. In: E-Dicionário de Termos Literários. Consulta realizada em 13/10/2021 no site: https://edtl.fcsh.unl.pt/encyclopedia/romanceiro/

CHARTIER, Roger. Cultura escrita, literatura e história: conversas de Roger Chartier, Carlos A. Anaya, Jesús A. Rosique, Daniel Goldin e Antonio Saborit. Porto Alegre: Artmed, 2001.

CHAVES Flávio Loureiro. História e Literatura. 3 ed. amp. Porto Alegre: Editora da UFRGS, 1999.

CARVALHO, José Murilo de. A Formação das Almas: O Imaginário da República no Brasil. São Paulo. Companhia das Letras: 1990.

CASTRO-GÓMEZ, Santiago; GROSFOGUEL Ramón. El giro decolonial: reflexiones para una diversidad epistémica más allá del capitalismo global. Bogotá: Siglo del Hombre Editores; Universidad Central, Instituto de Estudios Sociales Contemporáneos y Pontificia Universidad Javeriana, Instituto Pensar, 2007.

FLECK, Gilmei Francisco. O romance histórico contemporâneo de mediação: entre a tradução e o desconstructivismo - releituras críticas da história pela ficção. Curitiba: CRV, 2017.

FREITAS, Maria Teresa de. Literatura e história: o romance revolucionário de André Malraux. São Paulo: Atual, 1986. 


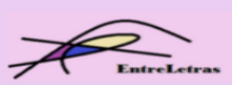

LARIOS, Marco Aurelio. Espejo de dos rostros. Modernidad y postmodernidad en el tratamento de la historia. In: KOHUT, Karl (Org.) La invención del pasado: La novela histórica en el marco de la postmodernidad. Vervuert Verlagsgesellschaft, 1997.

MARTINS, Wilson. A tentativa Iconoclástica. Rio de Janeiro: Jornal do Brasil, jul/1980. MEIRELES, Cecília. Romanceiro da Inconfidência. Rio de Janeiro: MEDIAfashion, 2008.

OLIVEIRA, Marcio da Silav O Santo Inquérito, de Dias Gomes: recepção e resistência no moderno teatro brasileiro. In: FLECK, Gilmei Francisco.; OLIVEIRA, Marcio da Silva; CERDEIRA, Phelipe de Lima. (Orgs.). Imagens da América - representações, expressões, resistências. Curitiba: CRV, 2020, p. 251-276.

PESAVENTO, Sandra Jatahy. História e História Cultural. 2.ed. Belo Horizonte: Autêntica, 2005.

SHARPE, Jim. A história vista de baixo. In: Burke, Peter (Org.). A escrita da história: novas perspectivas. Tradução de Magda Lopes. São Paulo: Editora Unesp, 2011. p. 39-64.

SOUZA, Valmir de. História e literatura: uma relação de amor e ode em História do Brasil de Murilo Mendes. Estudos Históricos (Rio de Janeiro), v. 21, n. 41, p. 45-58, 2008.

WHITE, Hayden. Trópicos do discurso: ensaio sobre a crítica e a cultura. São Paulo: Editora da Universidade de São Paulo, 1994.

Recebido em 20 de novembro de 2021.

Aceito em 03 de janeiro de 2022. 